\title{
Respite Service for the Elderly of the Belt and Road: A Zhejiang Story
}

\author{
Shiming Tang, Wenjie Ge ${ }^{*}$, Changjuan Guo, Lidan Xu \\ Hangzhou Normal University \\ Hangzhou, Zhejiang, China \\ *Email: 1377021730@qq.com
}

\begin{abstract}
In 2011, Chinese society has entered an aging society in an all-round way. In 2030, it will overtake Japan and become the country with the highest degree of population aging in the world. Zhejiang and Hangzhou are the first areas in the country and the whole province to enter the aging society. In order to cope with problems of aging society, problems of the high aging of the population and problems of empty nest families, to solve the problem of home care for the elderly, to innovate the service for the elderly, this project selects 25 communities under the jurisdiction of Tianshui Street, Changqing Street and Xiaoying Street in Hangzhou as the typical communities. Project group summarizes the typical experience and exploring newly respite service mode which supports of 9073 mode and 9064 mode with Chinese characteristics and on the basis of long-term care at home. In addition, it also exerts a positive far-reaching impact on sustainable development, economic innovation and harmony and stability of provincial and municipal governments.
\end{abstract}

Keywords: Respite Service, Care hub, the Belt and Road, Zhejiang Story

\section{BACKGROUND}

Most of the western developed countries have entered the aging of population under the background of basically realizing modernization. However, China faces with multiple challenges of aging of population aging, the aged aging and the empty-nest, under the background of unrealized modernization. The research group carried out research on typical communities in Hangzhou, summarized typical experience, explored new respite service mode based on long-term care at home, and solved the problem of home care for the elderly, which played a complementary role in implementing the pension policy of the party and the government.

This project selects 25 communities under the jurisdiction of Tianshui Street, Changqing Street and Xiaoying Street in Hangzhou as the typical communities, whose area is 5.46 square kilometers, with a population of 187 thousands. Among typical communities, Cangqiao community, Wangma community and Xiaoying community have become the work innovation demonstration communities. According to the population statistics of typical communities in Hangzhou, the population over 60 years of age accounts for about $15 \%$ to $20 \%$ of the total population. Over 80 years of age accounts for $15 \%$ to $20 \%$ of the elderly population. In 2030 and 2040, aging population of Hangzhou and Zhejiang are expected to break through $35 \%$ and $1 / 3$ respectively. At the same time, the proportion of elderly households empty nest living alone in urban is rising. Compared to $1 / 3$ of the total number of cities in the country, the number of streets in Hangzhou lakeside and other streets is more than doubled. It is expected that by 2015 , the proportion of elderly households empty nest living alone in Urban can reach $90 \%$. The population of the typical community in Hangzhou is increasing at a rate of about $5 \%$ per year. At the same time, the population is facing with the superimposed pressure of aging of population, aging advanced populations and family becoming empty nest. The path of the 9073 or 9064 of China's endowment determines the dominant position of home endowment. Providing for the elderly is facing with the following three problems:

\section{A. Phenomenon of Survive with Serious Illness, 2/3} Remaining Time Live with Disease.

With the time passing, the tissues, organs and related physiological functions decline, senile ones change, decreased health status decrease, the prevalence rate rise. According to statistics result of the survey, senior citizens have to spend their $2 / 3$ remaining time with serious illness.

$65 \%$ to $70 \%$ of the elderly suffer from varying severity, a variety of age-related diseases. At the same time, disabled elderly people keeps increasing. The available health care resources are highly demanded at present, and will become scarce while aging population keeps increasing.

\section{B. Phenomenon of 8421 Inverted Pyramid Structure, and} Family Members Overloaded by Senior Home Care.

Analysis report of the aging trend shows that urban families have entered the 421 structure model. That is, a family, a middle-aged husband and wife have four elderly but only one child. By 2020, there will be " 8421 " family structure, that is, eight aged old men, four elderly, a couple, one child.

Research data shows that problems related to senior home care become more and more serious, and care loads become heavier and heavier. This study confirms that long-term care for the elderly, especially those who are sick, requires a large investment of family members in energy and time, including daily activities in accordance with laundry, cooking, action, taking a bath and going toilet. Taking into account their own work and their own family duty, family members or the elderly caregivers are over loaded, the heavy care work and the huge economic costs bring them some psychological stress and life stress and social stress.

Furthermore, long-term senior home care forced family member caregivers to reduce interpersonal communication, resulted in a sense of loneliness and helplessness, lead in 
anxiety, depression and other negative emotions. In fact, family members as the caregivers are tied with greater psychological pressures than physical ones. Therefore, family members of elderly are in urgent need of some relaxation to relieve their burden as caregivers.

C. Phenomenon of Serious Shortage of Aging Cares, Only $5 \%$ of Elderly People are able to Enjoy their Rest Life in Nursing Home for Elderly Men.

Organizational nursing home for elderly men can offer professional care, reduce family burden, make new friends and enrich the spiritual life. However, in most cities, public nursing beds are limited and in short supply, and it takes two to three years to approach.

The majority of private cares are leased on premises, with small-scale operation whose hardware and software facilities are limited. It is difficult to tie up the clinic units and medical drugs. At the same time, private agencies prefer to choose a relatively independent place that is difficult to access transportation and to implement security measures. Therefore, most of the elderly prefer to stay at home and to be cared by family members. While the population of disability elderly people climbing high, many family members become exhausted.

\section{THEORETICAL FRAMEWORK}

Respite service is the provision of a series of temporary, supportive alternatives to the care of the aged disability, allowing their caregivers to enjoy temporary relaxation and rest. Beginning in 1960, some developed countries such as Australia, tried to develop some standard implementation for senior home care respite services while government subside about one half cost. The United States and the United Kingdom later improved and promoted senior home care with offering elderly ones respite service one week per year. Germany and other Europe countries contributed a lot to the standard long-term care system in the field of elderly rehabilitation, pension and nursing complement.

Chinese research started at 2000, Hong Kong and Macao recognized and practiced the Aging in place. Zhejiang province and Hangzhou city are the first ones in mainland to enter the aging society. In accordance with the policy of 9073 or 9064 which means institutional cares' bed limitation at $5 \%$ while other $90 \%$ of elderly people should take senior home care, this research team contact some pilot field study to meet related demands.

Since 2002, the relevant members of the project group selects 25 community under the jurisdiction of Tianshui Street, Changqing Street and Xiaoying Streets in Hangzhou as the typical community to carry out a survey by the implementation of the Zhejiang Provincial Academy of Social Sciences project "city home-based care services mechanism" and so on. Through the promotion and implementation of the work innovation of "eight one", "visiting people everyday", "door-to-door service to home", "neighborhood to see households", "pairing help in place" and "four to" service providers, we have improved the community service of home care for the aged. The "eight one" includes a file service for senior well informed mental and physical care, a guard network service for senior monitoring care, a on line help service for senior responsive care, a mediator service for promising care, a team service for comprehensive social care, a pager for emergency care, a chat room service for mental hygiene care, a visiting room service for support care. In the typical community, the introduction and exploration of the respite service are better adapted to the aging of the family structure.

\section{EXPLORATION}

The research is focused on the completion of a comprehensive well-off society of Chinese dream, combined with the operational standard on senior home care in Europe and the advanced experience on respite service in United States, its team works support each other and develop some local characteristics for Chinese senior home care 9073 mode and 9064 mode.

Zhejiang Province, in recent years, efforts to implement the senior home care with number policy to support respite services. Provided with resourceful first-hand information, this survey reaches desirable summary and innovation from the grassroots and thus improves greatly the system mechanism on senior home care respite services.

At the same time, the research group in this paper has taken the typical community as an example, and has gradually formed a typical benchmark for community work. It has realized the new normal of professional volunteer service and supports of multi-disciplinary expert team, and achieved twice the result of work innovation.

The research group got strong support from Australia, Europe, America, Hong Kong, Macao and Taiwan, especially the Yangtze River Delta urban and rural social workers. It enriched the work content and completed the promotion goal.

\section{RESULTS}

With continuing to prefect relative projects about "The service guarantee mechanism of empty nest elderly and its innovation", "Solving the problem of home old-age care" and other issues, the research group compared to professional standards of EU, America, Japan, Hong Kong, Taiwan and so on, the docking of the developed areas' long-term care system research, explore the promotion of respite care standards and system, discusses the training and guidance to the community center hospital. Problems such as the operability and standardization of the respite service have been solved. In order to further promote the "respite service", we should establish a reasonable standard and evaluation system, and play a supplementary role in implementing the pension policy of the party and the government.

This research group' research on suggestions to promoting and perfecting respite care, which has become the focus of the important media in Hangzhou, Zhejiang, the Yangtze River Delta region and the country in recent years, and has a positive and far-reaching impact on sustainable development, economic innovation and harmony and stability of provincial and municipal 
governments .

Respite service research is turning crisis into opportunity. It promotes warm, steady and popular sustainable development of "making our professional family trust", the happy community safe" warm, stable and popular. The team used respite service in typical communities as the base for data collection, service tracking and personnel training practice, which greatly promoted the improvement of respite service quality in these communities.

Breathing group in Hangzhou City, Zhejiang Province, a typical community service pilot as base, greatly promote the breathing to improve the quality of these communities.

\section{V.PROSPECT}

\section{A. Improving the Quality of Life and Promoting Family Harmony}

Compared to the housekeeping services in the home market, the professional services supported by teamwork which is provided by the respite service are more favorable for the recovery, nursing and treatment of the elderly, providing professional service benchmarks for the elderly's children and caregivers. Survival of the elderly, especially elderly dementia, disability groups can therefore get professional care and treatment, improving the quality of survival. The respite service can also effectively reduce the care burden of the caregivers and solve the family's long-term care problems.

B. Striving for Accomplishing in one's old Age and Supporting Mutual Assistance

After the reform and opening up, the society is full of vitality and the life span continues to grow. Respite service is the best platform for the activity "old people" to utilize their available energy to help "very old elderly". Respite service extension of the "mutual assistance", can transform the negative energy such as "square dance aunt" and "punctured tire" and so on into positive energy.

C. Closing to the Needs of the Reality and Achieving Win-win Cooperation

The respite service is a kind of security of happiness of working children are relieved to work and elderly members are assured of their retirement. Cooperative research group and tourist attraction and pensioners in Nice France, University of Lugano, Switzerland show that: the development of campus of University of Lugano respite services can greatly increase employment and promote development.

It is worth pointing out that solving the problem of old-age care and summarizing the typical experience, the path innovation of respite service in Zhejiang can combine French migratory bird pension model and Swiss paradise pension model to achieve complementary advantages and win-win cooperation.

\section{ACKNOWLEDGEMENT}

This paper was a particial achievement and financially supported by the All-China Federation of Returned Overseas Chinese Project (17DZQK203)“Zhejiang Stories on the Belt and Road People's Connectivity" and the 4th Acadmic Conference Project for Zhejiang Provincial Federation of Social Sciences (Sub-forum 201830) "Zhejiang Hub Construction for the Belt and Road".

\section{REFERENCES}

[1] Tang Shi Ming. Old-age vulnerable groups home care. J. Hangzhou (Weekly).12(2012): 37-38.

[2] Tang Shi Ming. A Preliminary Analysis of Making Local Standards for Respite Care in Zhejiang Province. J. 2016-10-11.China Development Network.

[3] Tang Shi Ming. Creation and Demonstration of Urban Empty Nest Service Guarantee Mechanism. J. Chinese Journal of Gerontology.20 (2008)2046-2047. 